\title{
Foreword by Eurostat
}

This collection of contributions is one in a series of publications commissioned for the European Commission's Environment Directorate General and Eurostat, the Statistical Office of the European Communities, under the reference title Towards Environmental Pressure Indicators for the EU (TEPI). It should be seen as a first background document to the 'Environmental Pressure Indicators Project', providing a general overview of the main issues covered by the project.

The TEPI series consists of a set of four closely related volumes, aimed at raising awareness of the pressures put on the environment as a result of human activity. This is done through the creation of a framework for the regular production of environmental pressure indicators. These indicators are intended as tools for environmental policy-making at European Union level as well as providing information to the general public. Each volume is split into ten parts, representing each of the policy fields covered by the project, that is, Air Pollution, Climate Change, Loss of Biodiversity, Marine Environment and Coastal Zones, Ozone Layer Depletion, Resource Depletion, Dispersion of Toxic Substances, Urban Environmental Problems, Waste, Water Pollution and Water Resources, based on the themes of the 5EAP. ${ }^{1}$ The starting-points of each volume have been the results of two surveys of environmental experts, carried out by Eurostat (see Editors' introduction).

The other volumes in the series are:

1. Towards Environmental Pressure Indicators for the EU, first edition $1999^{2}$ This is Eurostat's reference publication on pressure indicators. It contains data for the set of 60 core pressure indicators selected by expert survey (see list on page xii and Editors' introduction).

2. Towards Environmental Pressure Indicators for the EU - Indicator Definition $^{3}$

This second background document provides a description of the policy fields and their respective indicators (mainly those identified as core indicators, see (1) above), and proposes recommendations for further research activities.

3. Towards Environmental Pressure Indicators for the EU - An Examination of the Sectors ${ }^{4}$ 
This third background document contains six reports drafted by national statistical offices, describing the links between the indicators and the economic sectors agriculture, energy, industry, tourism, transport and waste management.

The Working Documents, together with Methodology Sheets providing methodological background to the indicators, are available (or are intended to be made available) on the TEPI Web site (http://e-m-a-i-1.nu/tepi/), which provides a comprehensive description of the work done by Eurostat on pressure indicators and gives full contact details of the project team. Another related Web site (http://esl.jrc.it//envind), situated at the European Commission's Joint Research Centre in Ispra (Italy), provides a discussion forum on research aspects of the project.

Recent political priorities have focused on developing indicators on sectoral integration, that is, integrating the environmental dimension into sectors (mainly transport, energy, agriculture and industry). This sectoral aspect was already foreseen in the work on pressure indicators (see (3) above); however, the reallocation of priorities means that some of the future work referred to in these publications, for example the condensation of the indicators into a set of indices, has now moved further down the political agenda, although such a development is not excluded at a later stage.

The reader should be aware that the opinions expressed in these documents do not necessarily reflect the official viewpoint of the European Commission.

\section{NOTES}

1. Fifth Environmental Action Programme: Resolution of the Council and the Representatives of the Governments of the Member States meeting within the Council of 1 February 1993 on a Community programme of policy and action in relation to the Environment and Sustainable Development - Towards Sustainability (OJ 93/C 138 of 17.5.93).

2. ISBN 92-828-4978-3, EUR 36 (excl. VAT) from Office for Official Publications of the European Communities, L-2985 Luxembourg (first edition June 1999; second edition to appear in 2000).

3. Availabe as a Working Document (publicity to be provided on the TEPI Web site (http://em-a-i-1.nu/tepi/)

4. See note 3 . 


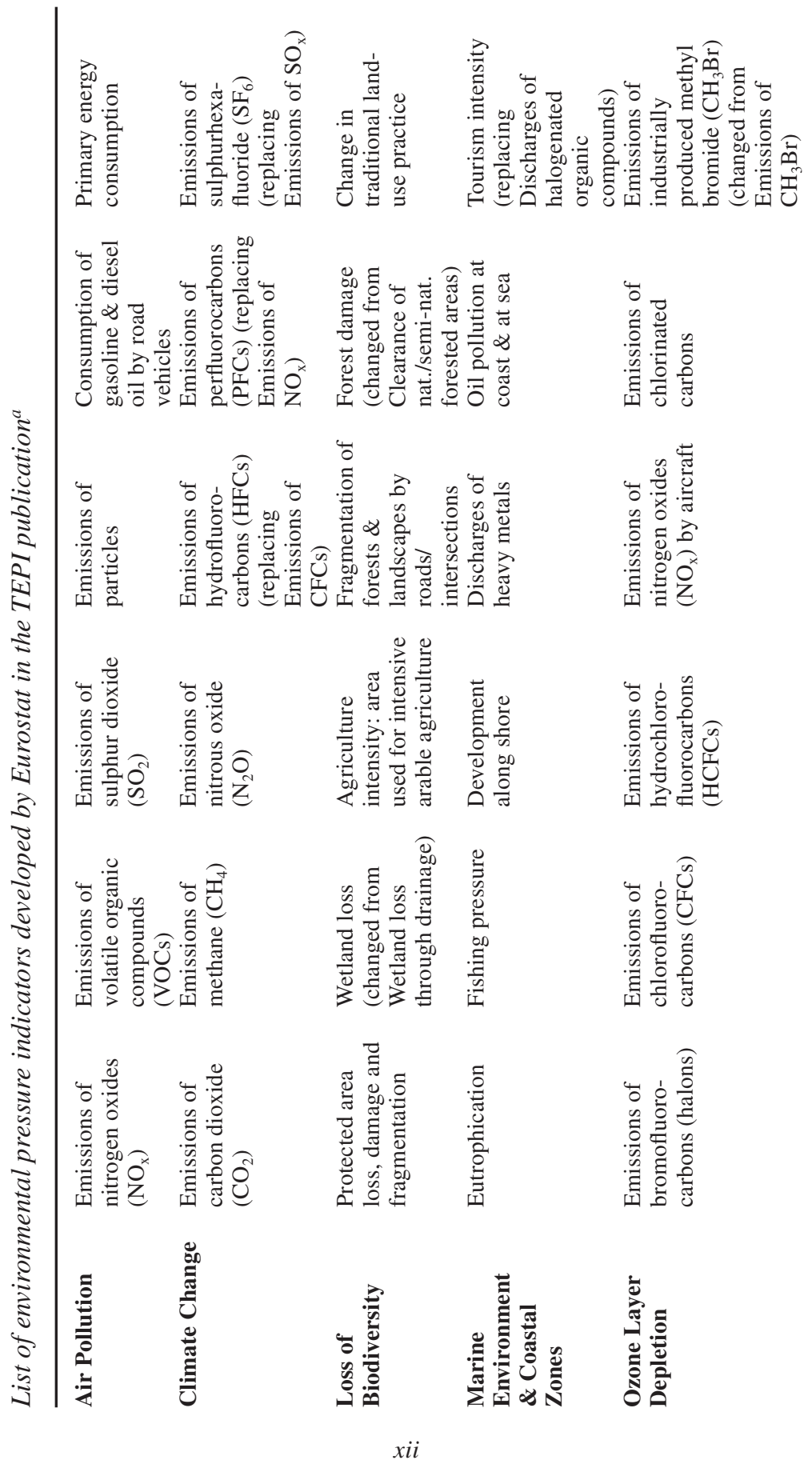




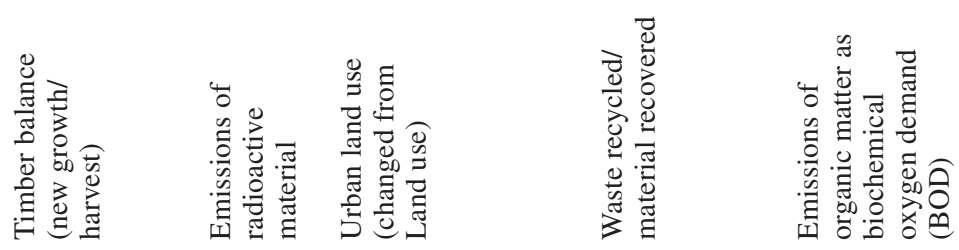

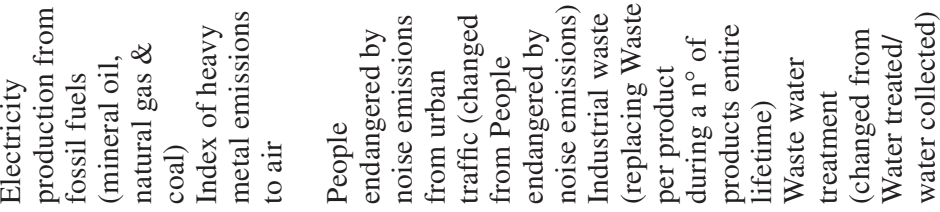

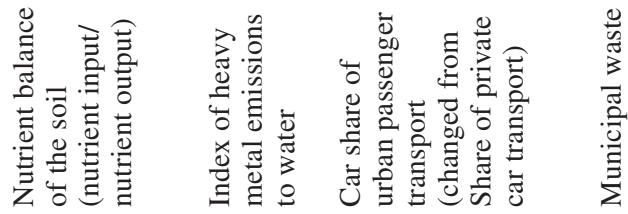
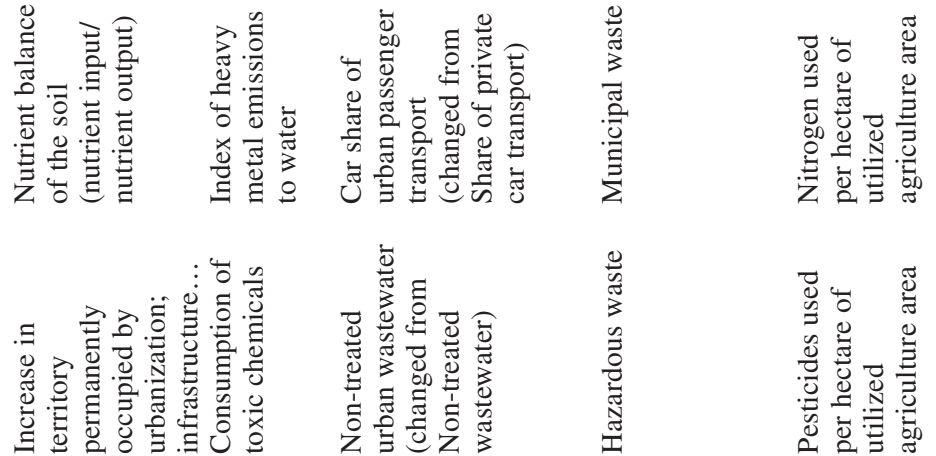

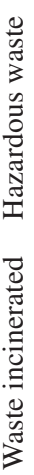

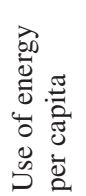

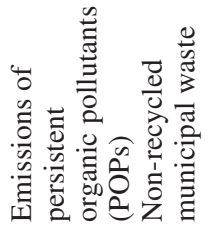

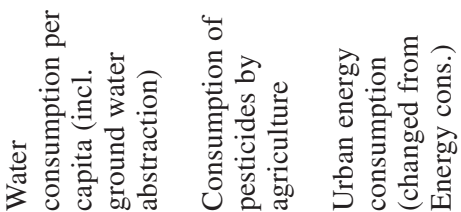

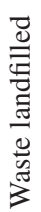

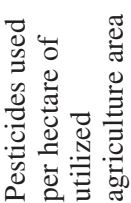

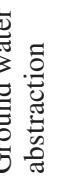
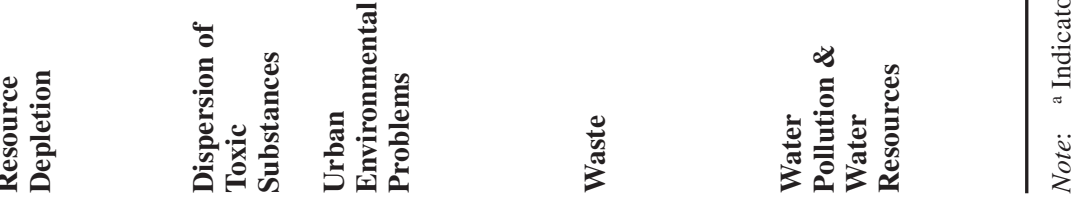